\title{
RASGOS GEOLÓGICOS DEL RÍO RÍMAC, ABASTECIMIENTO DE AGUA EN SU CONO DE DEYECCIÓN
}

\author{
GEOLOGICAL TRAITS OF RIMAC RIVER, \\ WATER SUPPLY AT ITS EVACUATION CONE
}

\author{
Pedro Tumialán de la Cruz ${ }^{1}$
}

PRESENTACIÓN: MAYO 2016

ACEPTACIÓN: JULIO 2016

\section{RESUMEN}

El río Rímac abastece de agua superficial y subterránea a la población de Lima. Su cono de deyección, de 30 $\mathrm{km}$ por $20 \mathrm{~km}$, está formado por un suelo permeable fluvial del Cuaternario antiguo. Su basamento es roca compacta de edad más antigua a la edad cuaternaria (Cretáceo inferior, medio, superior). Con la finalidad de incrementar el caudal del río Rímac, existe la posibilidad de tomar agua de la Laguna de Huacracocha, ubicada entre Ticlio y Morococha, con un túnel de $3.5 \mathrm{~km}$ rumbo $\mathrm{S} 78^{\circ} \mathrm{W}$. El otro proyecto consiste en captar parte del agua del río Mantaro con un túnel de $45.4 \mathrm{~km}$ rumbo S61030'W.

Palabras clave: Geología, rasgos geológicos, abastecimiento de agua, cono de deyección.

\begin{abstract}
Rimac river supplies superficial and below ground water to Lima city, its $30 \mathrm{~km}$ by $20 \mathrm{~km}$ evacuation cone is composed by a fluvial permeable soil from antique Quaternary. It is made of compacted sedimentary rock older than Quaternary date (lower and middle upper Cretaceous). In order to increase the Rio Rimac's caudal, water from Huacracocha Lagoon (between Ticlio and Morococha) may be taken with a $3.5 \mathrm{~km} \mathrm{S78^{ \circ }}$ W tunnel. The other project may be the collection of part of Mantaro river's waters with a $45.4 \mathrm{Km} \mathrm{S61030'W}$ tunnel.
\end{abstract}

Keywords: Geology, supply, water, Lima, evacuation cone. 


\section{LA COSTA PERUANA, ZONA DESÉRTICA}

El Perú se ubica en la zona tropical. La costa posee un clima lluvioso con vegetación exuberante. Estas condiciones climáticas han cambiado por efecto de la corriente fría de Humboldt, que viene del polo sur y migra paralela a la costa peruana hasta la punta de Cabos, en Piura, para proseguir su curso al oeste. Interviene, en este cambio climático, el macizo rocoso de la cordillera de los Andes, paralelo a la costa peruana. Sus rumbos de sur a norte son NO, NNO, NS, NNE; es una barrera natural que dificulta la migración de los vientos cálidos de la selva a la costa, a la que se opone, además, el efecto del anticiclón del Pacífico, de aires fríos, ubicado a los $23^{\circ}$ sur en el océano Pacífico. Estas tres condiciones naturales dan a la costa un clima desértico con una aridez en su mayor extensión (figura 1).

\section{VALLES COSTEROS CON PRESENCIA Y AUSENCIA DE AGUA}

En medio de esta aridez por la falta de agua, hay zonas que reciben este elemento de la cordillera occidental de los Andes peruanos. Son cincuenta valles que la reciben (figura 1). Entre ellos se encuentra el valle del río Rímac. Es ahí donde se ubica la ciudad de Lima.

Por el escaso caudal de agua, muchos valles reciben poca o ninguna cantidad durante todo el año.

Se debe explicar por qué estos valles reciben poca agua o no la reciben durante todo el año. Los valles áridos la obtienen de manera subterránea, por debajo del nivel freático. Es gracias a los estudios geofísicos de resistividad eléctrica que se detecta la profundidad del nivel freático. Además, debido al bombeo de pozos artesianos, se consigue agua subterránea para consumo humano y, gracias al método de riego por goteo, se tendrá agua necesaria para el riego de sembríos.

En el suelo del Cuaternario antiguo, el cual se ubica en el valle Culebras (Huarmey, Lima), hubo agua hasta la costa, incluso con la presencia de grandes bloques de rocas por los antiguos aluviones entre las cotas 1800 a 2 $200 \mathrm{msnm}$. Actualmente, en este sector del valle pedregoso, no se desarrolla ampliamente la agricultura. A cota menor, el terreno no es pedregoso por ausencia de aluviones y es propicio para la agricultura. En esta zona, se realiza el riego por goteo con agua subterránea que se extrae por bombeo y se siembran productos de exportación como los algarrobos.

El agua es vida. Los valles secos necesitan de este elemento, que proviene del nivel subterráneo. A fin de asegurar su presencia, muchos agricultores han construido en las partes altas de la cuenca fluvial, de forma artesanal, muchas presas pequeñas de tierra y de arcilla, cantos angulosos, y cantos rodados de dos metros de altura, todos los cuales se llenan hasta el tope de agua en la temporada de invierno. Cuando cesa la lluvia, en los meses comprendidos entre mayo

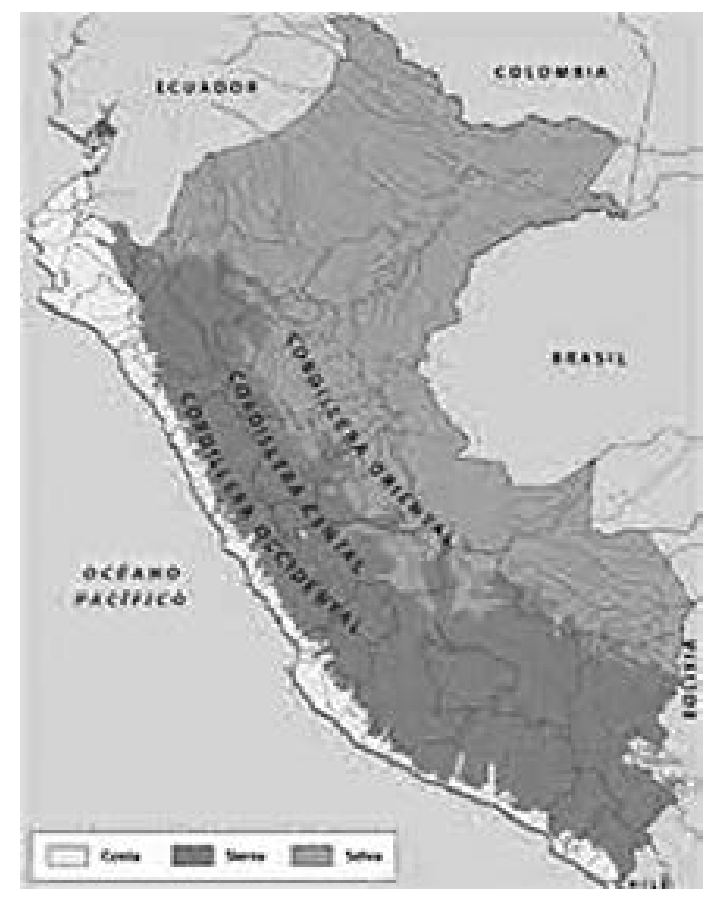

Fig. 1. Mapa fisiográfico del Perú. 
y octubre, el agua de las mini presas de tierra baja en forma lenta por el suelo permeable del fondo del valle y alimenta a los pozos artesianos durante la época de sequía en las partes bajas de los más secos. Gracias a este sistema de irrigación, estos valles desérticos tienen agricultura para consumo local y para exportación.

\section{EL VALLE DE LIMA: DATOS HISTÓRICOS}

Francisco Pizarro llegó a Tumbes en 1532. Luego, se dirigió a Cajamarca y al Cusco. Al final de su recorrido, llegó al extenso valle de Jauja, que recorre el río Mantaro, de $45 \mathrm{~km}$ de largo y $12 \mathrm{~km}$ de ancho, con rumbo NO a SE y tiene ubicado en su parte norte a la laguna de Paca (Paredes, 1994). Inicialmente, todo ese extenso terreno fue el valle de Jauja. En el diccionario, 'jauja' significa ciudad de prosperidad y felicidad. Pizarro, debido a las condiciones favorables que presentaba, fundó la capital del Virreinato del Perú en Jauja el 25 de abril de 1534.

Posteriormente, le comunicaron la presencia de un extenso valle en donde desembocaba el río Rímac, que en lengua nativa se llamaba 'limac', palabra que significa "río hablador", por los ruidos que hace al transportar las piedras en forma de cantos rodados desde la cordillera.

Francisco Pizarro recorrió el extenso valle de clima agradable y descubrió que era un terreno sin lluvias, truenos ni rayos. Asimismo, desde el punto de vista estratégico, se ubicaba cerca al mar, lo cual era útil para huir de cualquier amenaza. Por lo expuesto, el conquistador fundó por segunda vez la capital del Virreinato del Perú, esta vez en Lima, el 18 de enero de 1535. Después de trazarse los límites de la ciudad, se nombró a un primer alcalde, Nicolás de Ribera (el Viejo), quien estuvo con Pizarro el día que fue asesinado por los almagristas. El río Limac, luego Rímac, dio lugar al nombre de Lima, la capital del Virreinato del Perú.

\section{GEOMORFOLOGÍA DEL CONO DE DEYECCIÓN DEL RÍO RÍMAC}

La ciudad de Lima se emplaza en el cono de deyección del río Rímac. Al norte, limita con el cono de deyección del río Chillón; al sur, con las arenas de la playa Conchán, arenas de Villa El Salvador, elevaciones de los cerros de las Casuarinas, los Álamos, Ate y Vitarte; y al NE, con los cerros de Comas, Independencia, La UNI, el Rímac, cerro San Cristóbal y los cerros de San Juan de Lurigancho.

En medio de este cono de deyección, se pueden apreciar elevaciones aisladas como los cerros Lampa de Oro, El Agustino, San Cosme, Los Pinos, el Morro Solar, que tienen alturas de hasta 200 m sobre la altura promedio de la ciudad de Lima. Destaca el cerro San Cristóbal, con $450 \mathrm{~m}$ sobre el suelo de Lima.

El cono de deyección del río Rímac, donde se emplaza la ciudad de Lima, tiene una extensión, a lo largo del borde litoral, de $30 \mathrm{~km}$ desde el extremo SE de los pantanos de Villa hasta el extremo norte de San Martín de Porres y $20 \mathrm{~km}$ desde los acantilados de Miraflores hasta Vitarte (figura 2). Si fuera de una extensión mucho mayor, sería un delta, como lo es el del Nilo, donde se desarrolló la cultura egipcia.

El cono de deyección del río Chillón es angosto. En su desembocadura, están las rocas de las formaciones Puente Inga y Puente de Piedra del Cretáceo inferior. Las aguas subterráneas son alimentadas por el aquel río y se mezclan con las aguas subterráneas alimentadas por el Rímac.

El cono de deyección del río Lurín no se une con el cono de deyección del Rímac. Entre ambos, se encuentra el suelo arenoso de la playa Conchán, Lomo de Corvina, Villa El Salvador, y los cerros de San Juan de Miraflores y Villa María del Triunfo (figura 2). 


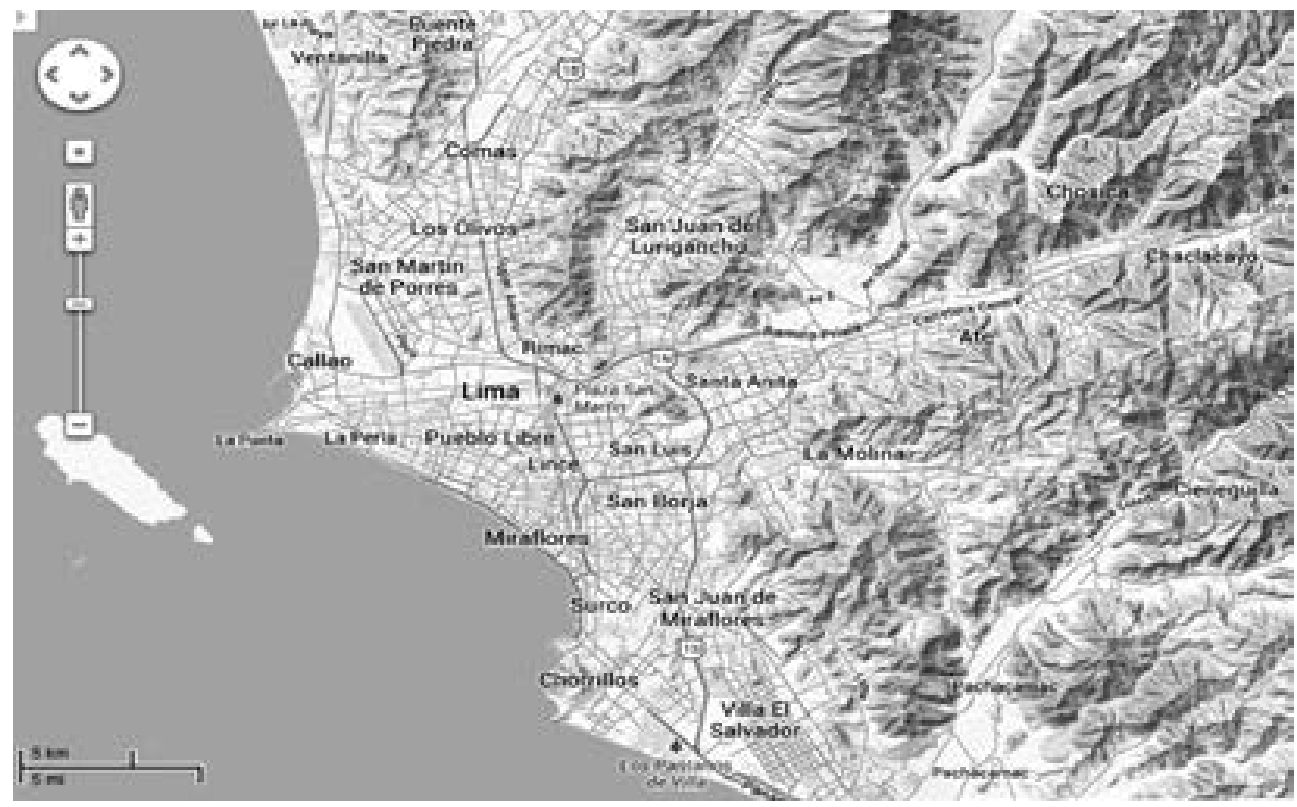

Fig. 2. Cerros alrededor del cono deyección del rio Rímac.

\section{GEOLOGÍA DE LA CUENCA DEL RÍO RÍMAC Y DE SU CONO DE DEYECCIÓN}

El río Rímac se forma a 3400 msnm por la confluencia del río Blanco con el Yauliyaco. Este último nace en Ticlio, a $4820 \mathrm{msnm}$ de altura, y el Blanco es alimentado por el nevado Tatajaico a 5 000 msnm de altura. En su recorrido, el río Rímac, antes de llegar a Chosica, recibe el aporte del río Santa Eulalia en su margen derecha.

El río Rímac tiene una cuenca fluvial más amplia que las de los ríos Chillón y Lurín. Esta cuenta escasa vegetación en sus flancos, lo cual favorece una mayor erosión de suelo. Ese fenómeno lo ocasionan las lluvias que van al lecho del río.

La edad del valle del río Rímac se estima en 1000000 de años. Todo río erosiona el fondo de su lecho. Si consideramos que la erosión que produce el río Rímac por año es $0.0001 \mathrm{~m}$ en 1000000 de años, se conseguirá una erosión de $1000 \mathrm{~m}$, es decir, $1 \mathrm{~km}$ de erosión total. Luego, las grandes cumbres a ambos lados del río, cuyas alturas alcanzan los $1000 \mathrm{~m}$ sobre el lecho del río, han sido formadas por la erosión del río Rímac. Todo el material de erosión fue depositado en el cono de deyección del río Rímac ya referido, donde se ubica la ciudad de Lima.

A lo largo del río Rímac y sus afluentes, se ubican secciones transversales en forma de u. Esto quiere decir que aparecen secciones de valle glaciar sobre los $4000 \mathrm{msnm}$ de altura, y transversales en forma de v o trapecio invertido a menor altura. Todas estas forman valles fluviales, valles aluviales, valles fluvio-aluviales y secciones con paredes verticales, lo cual origina cañones como el del Infiernillo u otros combinados con paredes verticales y en forma de v, como sucede en Río Blanco.

Debemos mencionar la geodinámica externa del río Rímac, que da lugar a aluviones (huaycos), desprendimientos de rocas, deslizamientos y asentamientos que afectan a las obras viales y a las poblaciones. La cuenca del río Rímac de las zonas altas, sobre los $2200 \mathrm{msnm}$ de altura hasta los 4820 msnm (Ticlio), se puede considerar como la zona «A» de lavado. Las aguas lavan el suelo de los flancos de los valles y la llevan al río. Eso se suma a la presencia de agua de lluvia. Todo ese material es depo- 
sitado a cota menor entre los 2200 a $1800 \mathrm{msnm}$ de altura entre Tambo de Viso hasta Surco, lo cual destroza las poblaciones ubicadas a lo largo de las terrazas fluviales, terrazas aluviales y terrazas fluvioaluviales. Este mismo fenómeno se produce en los ríos tributarios del Rímac, como el Santa Eulalia en el Huayco Loro. Lo mismo sucede en las diferentes quebradas como en la Pedregal, cerca a Chosica. A esta zona destruida por el aluvión la consideramos como la zona «B». A cota menor, donde termina el aluvión en cada uno de esos ríos o quebradas, se ubica la zona "C» solo de aguas turbias, porque lleva, en suspensión, arena, limo y arcilla. Por lo expuesto, no tenemos aluviones en la parte baja del río Rímac, es decir, en su cono de deyección, donde está la ciudad de Lima.

El río Rímac recibe el lavado de los relaves de las minas explotadas o en explotación. Desde la parte alta y a menor cota, se presentan los relaves de las minas de Ticlio, Casapalca, Yauliyaco, Huampar, Colqui, Millotingo, Pacococha, Germania, El Barón, Coricancha, El Farallón, Perubar y otras. Esta contaminación no solo afectará las aguas superficiales del río Rímac, sino también las aguas subterráneas que se depositan en el cono de deyección del mismo.

Geológicamente, este río y sus afluentes, de la parte alta al cono de deyección, han erosionado rocas sedimentarias de lutitas y volcánicos del Paleógeno-Neógeno con erosión de calizas del Cretáceo medio a superior y del Triásico-Jurásico, ubicadas a la misma altura de los volcánicos por fallas que levantaron estos bloques de calizas. A menor cota desde Corcona, en Chosica, hasta Vitarte, afloran intrusivos, en su mayoría de composición intermedia del Cretáceo superior, en una distancia de 30 $\mathrm{km}$. Más al oeste, se presenta el afloramiento de estos en los bordes del cono de deyección del Rímac (Palacios, Caldas y Vela, 1992).

En el mismo lugar, sobre el que está situada la ciudad de Lima, aparecen rocas volcánicas de la formación Casma del Cretáceo medio; rocas sedimentarias compactas de areniscas; lutitas, y calizas de las formaciones La Herradura, Marcavilca, Pamplona y Atocongo del Cretáceo inferior (Palacios et al., 1992).

El cono de deyección del río Rímac, en su borde oeste, termina en un acantilado. A la altura de Chorrillos, la altura del acantilado mide $80 \mathrm{~m}$, lo que se mantiene hasta San Miguel y desciende paulatinamente hacia La Punta, en el Callao, cuya cota es nula. Esto significa que el borde original del cono se prolongó hacia el oeste, en el mar, por una distancia de 2000 metros. En otras palabras, el borde llegaba a cota cero (0), similar al de La Punta en el Callao, que es parte del cono de deyección. La Punta no tiene acantilado, pues posee una defensa natural de las olas marinas, la isla San Lorenzo. En los lugares en los que no existe este tipo de protección, se observa acantilado en el cono de deyección, como en Chorrillos, Barranco, Miraflores, Magdalena, San Miguel y La Perla.

Consideramos la edad del cono de deyección en 1000000 de años. Es decir, pertenece al Cuaternario pleistoceno. El río Rímac, durante ese tiempo, no ha tenido un curso fijo. Más bien, ha divagado desde Chorrillos, en la depresión que baja de la Escuela Militar, a las depresiones en Barranco y la quebrada Armendáriz en Miraflores. En algunos sectores aledaños a la ribera actual del río Rímac, se observan terrazas fluviales como la que se encuentra en el puente Dueñas, en la avenida Perú. Al estudiar los cantos rodados del río Rímac, se concluye que todos son rocas ígneas volcánicas con composición andesítica e intrusivas. En su mayoría, poseen una composición félsica y provienen de la erosión producida por el río Rímac a las rocas de la franja volcánica cenozoica y al batolito de la costa explicados.

\section{HIDROGEOLOGÍA DEL CONO DE DEYECCIÓN DEL RÍO RÍMAC}

Gracias al aporte de agua del río Rímac, los once millones de habitantes de Lima pueden satisfacer sus necesidades de abastecimiento. Aquel se puede considerar una vena si lo comparamos con la extensión 
de su cono de deyección. Lo interesante es que alimenta de agua subterránea a todo el suelo del referido cono. La capital ha incrementado su población con la ubicación de viviendas en los bordes de los cerros de rocas intrusivas y rocas sedimentarias compactas de una edad más antigua al Cuaternario. El conjunto de estas viviendas forma una serie de asentamientos humanos que se abastecen de agua por efecto del bombeo de aguas subterráneas, que luego son almacenadas en tanques de almacenamiento a mayor cota de los asentamientos humanos.

Se debe considerar los lugares adicionales producidos por el afloramiento de agua subterránea. Uno de ellos es la laguna de La Molina, que, en el pasado, fue una cantera de donde se extrajeron materiales de construcción para las viviendas en la época colonial y comienzos del siglo XX de la era republicana. Su explotación se paralizó cuando la cantera llegó al nivel freático de las aguas subterráneas alimentadas por el Rímac. Posteriormente, el área se urbanizó hasta llegar al estado actual. Otro lugar de afloramiento de aguas subterráneas del rio Rímac es los Pantanos de Villa. El agua dulce presente ahí es alimentada por el agua subterránea de Lima, la cual migra por fracturas y fallas en las rocas compactas ubicadas al NE de los pantanos. El suelo del cono de deyección del río Rímac es un acuífero abierto no confinado. Este obtiene el agua desde el nivel freático hasta su basamento rocoso de rocas sedimentarias compactas y rocas volcánicas del Cretáceo inferior a medio. El nivel freático es de mayor cota cerca al río Rímac y el lecho del río está a una profundidad de $10 \mathrm{~m}$ de la superficie de su terraza fluvial. A mayor distancia del río, el nivel freático tiene menor altitud respecto al nivel del mar. Es decir, se halla a mayor profundidad de la superficie superior del cono de deyección y llega a las profundidades de la misma (de $70 \mathrm{~m}$. a $120 \mathrm{~m}$ ).

En 1951, en el acantilado frente a la playa Agua Dulce, en Chorrillos, a $10 \mathrm{~m}$ sobre el nivel del mar, afloraban cortinas de manantiales de agua dulce que

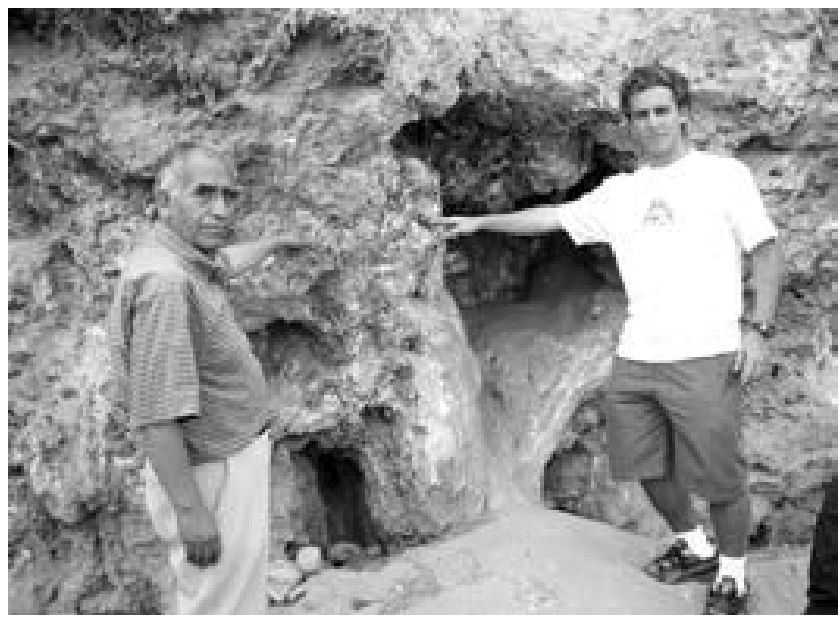

Fig. 3. Travertino en el acantilado de la costa verde formado por deposición de calcita por el afloramiento de las antiguas aguas subterráneas de Lima. correspondía al agua subterránea de Lima. En la actualidad, no vemos esos chorros de agua en el acantilado del suelo del cono de deyección, debido al exceso de bombeo en el área del cono. Actualmente, vemos vestigios de la cota superior del nivel freático del pasado en algunos bordes del acantilado donde no han sido cortados para extender el área de la Costa Verde. Ello se representa en la presencia de travertinos transportados, en el pasado, por las aguas subterráneas que disolvieron partículas finas de carbonato de calcio (calcita) del suelo del cono de deyección del río Rímac (suelo de Lima) y, al aflorar en el acantilado, depositaron travertinos (figura 3). El borde superior de estos está a $40 \mathrm{msnm}$, es decir, a media altura del acantilado. Hoy se puede evidenciar el afloramiento del agua subterránea del río Rímac en varios puntos de la Costa Verde a cota 0 , similar a la del mar. Dicho nivel freático ha bajado $40 \mathrm{~m}$, debido al exceso de bombeo de las aguas subterráneas en la ciudad. En otras palabras, en la terraza marina de la Costa Verde, el agua subterránea del cono de deyección está al nivel del mar. Esta se encuentra sobre el agua subterránea marina salada, porque la del cono de deyección posee menor peso específico respecto al peso del agua salada del mar. 


\section{CAPTACIÓN DE AGUA DE OTRAS FUENTES PARA INCREMENTAR EL CAUDAL DEL RÍO RÍMAC}

SEDAPAL capta una parte del caudal del río Rímac para procesar y dar agua purificada a la población de la ciudad. Gran parte se va al mar. El resto alimenta el agua subterránea del cono de deyección. Con mucha visión, se ha tratado de incrementar el caudal con el trasvase por medio de túneles que parten de las aguas de las lagunas de Marcapomacocha. Estas alimentan al río Santa Eulalia, que es tributario en la margen derecha del río Rímac. La presa de tierra de Yuracmayo, de 40 millones de metros cúbicos de capacidad, ubicada en la margen izquierda de la confluencia del Río Blanco con el Yauliyacu, almacena agua del deshielo de los nevados Tatajaico en invierno y abastece de agua por medio del Río Blanco, en verano, al Rímac.

Entre Ticlio y Morococha, se encuentra la laguna Huacracocha a una altitud de $4560 \mathrm{msnm}$ en la provincia de Yauli del departamento de Junín. Ahí es posible captar parte de sus aguas con un túnel de $3.5 \mathrm{~km}$ y un rumbo, desde el borde SO de la laguna, igual a $578^{\circ} \mathrm{W}$ (figura 4). De esa manera, llega al río Yauliyaco con una pendiente negativa de uno por mil. Esa agua saldría entre Casapalca y Ticlio. Este río, al unirse con el Río Blanco, forma el río Rímac.

La otra posibilidad es captar parte de las aguas del río Mantaro (antes de La Oroya) por medio de un túnel de $45.4 \mathrm{~km}$ con rumbo de $561^{\circ} 30^{\prime} \mathrm{W}$, una cota inicial de $3680 \mathrm{msnm}$ y una pendiente negativa de uno por mil, que desembocaría en el Yauliyaco a la altura de Chicla (figura 5). Al unirse con el Río Blanco, formaría el Rímac. Este segundo proyecto fue mencionado por el sabio Santiago Antúnez de Mayolo, quien lo formuló sin presentar estudios adicionales. Lógicamente, habría que realizar una serie de estudios geológicos y geotécnicos de ambos proyectos, lo cual sería materia de un estudio especial.

Si observamos ambos proyectos, descubriremos una distancia mayor en el trasvase del río Mantaro. Se trata de un túnel de $45.4 \mathrm{~km}$ comparado con la captación de las aguas de la laguna Huacracocha, que utiliza uno de $3.5 \mathrm{~km}$. El proyecto del trasvase que parte del río Huancabamba a la zona de Chiclayo se realizó con un túnel de $20 \mathrm{~km}$ de longitud y se terminó después de muchas décadas. Por eso podemos suponer que ejecutar el proyecto de un trasvase que partiera desde el río Mantaro sería muy remoto. El encargado de la captación de la laguna Huacracocha, con un túnel de

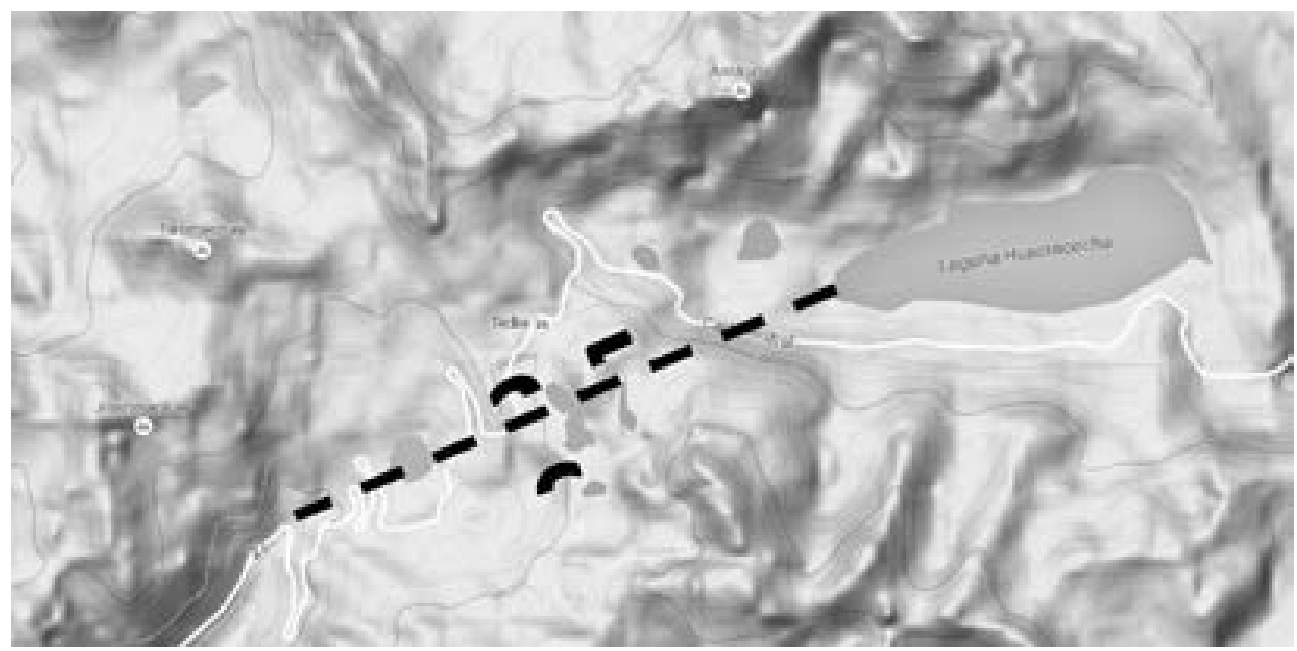

Fig. 4. Aguas de la laguna Huacracocha al río Yauliyaco. 


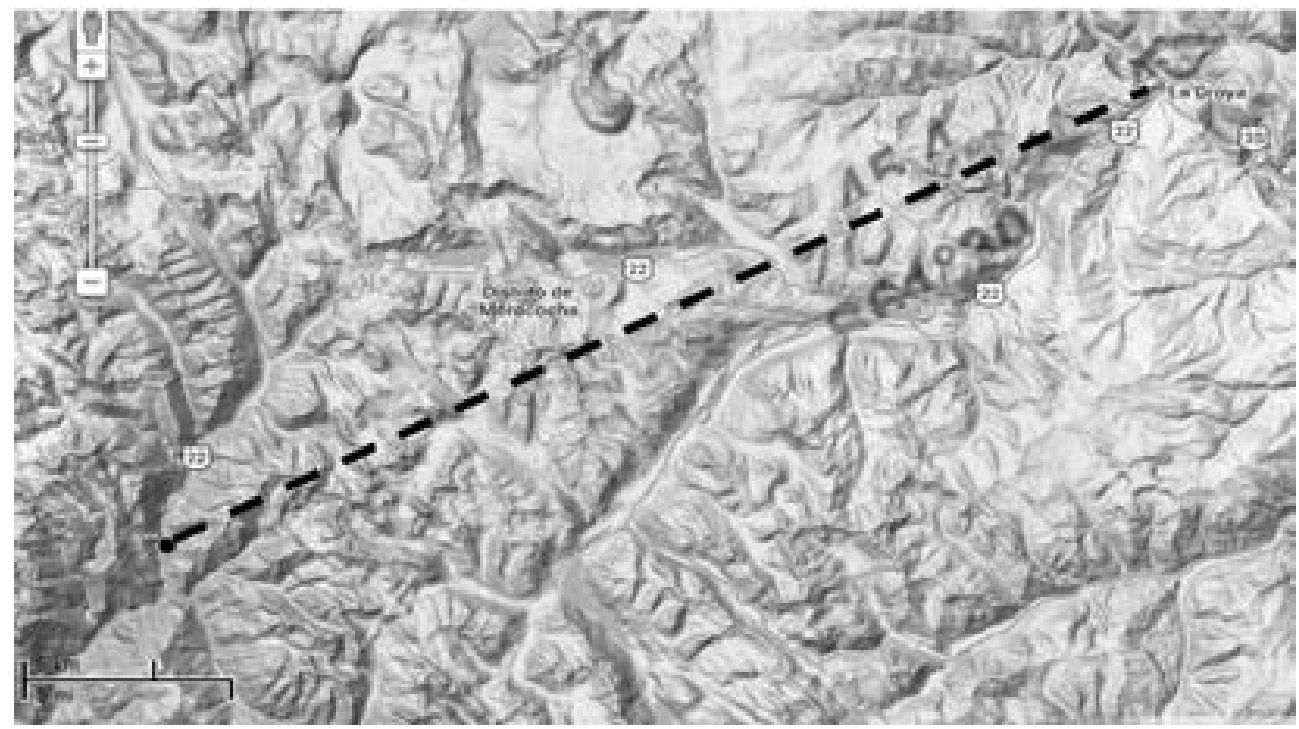

Fig. 5. Trasbase de agua de río Mantaro al río Yauliyaco.

$3.5 \mathrm{~km}$ de longitud, podría ejecutarse con mayor facilidad. Este proyecto sería atravesado inicialmente por suelos morrénicos del Cuaternario, rocas intrusivas dioríticas del Neógeno, Calizas de la formación Pucará del Triásico-Jurásico, lutitas de la formación Casapalca del Cretáceo superior al Paleógeno inferior y suelo morrénico del Cuaternario. Este último requiere de mucho sostenimiento al inicio y al final del túnel. El intrusivo y la caliza son rocas estables en el túnel. Las lutitas inestables presentarán muchos problemas de sostenimiento en el que, además, atravesará muchas fallas con problemas de sostenimiento y drenaje de agua superficial por las fallas. Todos esos aspectos requerirán un estudio geotécnico minucioso, materia de otro proyecto de investigación.

\section{REFERENCIAS}

[1] Palacio, O., Caldas, J., y Vela C. (1992). Geología de los cuadrángulos de Lima, Lurín, Chancay, Chosica. Ingemmet. Bol. 43. Serie A. Pág. 1-250

[2] Paredes, J. (1994). Geología del cuadrángulo de Jauja. Ingemmet. Bol. 48. Serie A. Pag. 1-150 